\title{
Levels and distributions of polychlorinated biphenyls in sewage sludge of urban wastewater treatment plants
}

\author{
GUO Li, ZHANG Bing, XIAO Ke, ZHANG Qinghua, ZHENG Minghui*
}

State Key Laboratory of Environmental Chemistry and Ecotoxicology, Research Center for Eco-Environmental Sciences, Chinese Academy of Sciences, Beijing 100085, China. E-mail: guoli_2008@163.com

Received 23 April 2008; revised 06 June 2008; accepted 15 June 2008

\begin{abstract}
Concentrations of polychlorinated biphenyls (PCBs) have been measured in sewage sludge samples from 8 urban wastewater treatment plants in Beijing, China. The PCB congeners were analyzed by isotope dilution high resolution gas chromatography/high resolution mass spectrometry method. The concentration of PCBs ranged from 65.6 to $157 \mathrm{ng} / \mathrm{g}$ dry weight (dw), with a mean value of $101 \mathrm{ng} / \mathrm{g} \mathrm{dw}$. The dioxin-like PCB WHO-TEQs (World Health Organization-Toxic Equivalents) of the sludge were lower than $1 \mathrm{pg}$ $/ g$ dw. Consequently, all the concentrations of PCBs in sludge samples were below the upper limit for land application according to the Chinese legislation law for agriculture use. The PCB homologue profiles in sludge samples were dominated by tri-CBs and tetraCBs. Similar distributions have been found in one of the Chinese PCB commercial products. The patterns of dioxin-like and indicator congeners observed in this study were quite similar in all samples. The predominant congener for dioxin-like and indicator PCBs were PCB-118 and PCB-28, respectively, while PCB-126 had the highest TEQ value.
\end{abstract}

Key words: polychlorinated biphenyls; wastewater treatment plant; sewage sludge; distribution

DOI: $10.1016 / \mathrm{S} 1001-0742(08) 62293-7$

\section{Introduction}

The utilization approach of sewage sludge as fertilizer to agricultural land is considered as an economical way to use the high amounts of sludge produced by the wastewater treatment plants (WWTPs) in China. Usually, sludge is often regarded as a potential manure resource, mainly because it contains high proportions of organic matter and abundant plant nutrients. However, it also consists of heavy metals and various persistent organic pollutants (POPs) (Cai et al., 2007; Eljarrat et al., 1997; Lazzari et al., 2000) which might have a negative impact on soil organisms and fertility. Because of their lipophilic nature, many POPs such as polychlorinated biphenyls (PCBs), polychlorinated dibenzo- $p$-dioxins and dibenzofurans (PCDD/Fs) and polychlorinated naphthalenes (PCNs) preferentially partition onto sludge during wastewater treatment. These organic pollutants enter the wastewater stream by direct or indirect release from households and industry or by atmospheric deposition on surfaces and then runoff into the wastewater treatment system (Blanchard et al., 2001; Katsoyiannis and Samara, 2004; Harrison et al., 2006).

PCBs are a class of 209 chemical compounds that are ubiquitous in the environment. Among the PCB congeners, 12 have similar toxicity to that of PCDD/Fs are assigned with toxic equivalency factor (TEF) values by the World

\footnotetext{
* Corresponding author. E-mail: zhengmh@rcees.ac.cn
}

Health Organization (WHO). Hence, these compounds are referred to dioxin-like PCBs. Additionally, 7 indicators have been selected to monitor PCBs to avoid the complexity involved in determining more congeners.

PCB commercial mixtures were widely used for different industrial applications such as dielectric fluids in capacitors and transformers, plasticizers in paints, adhesives, etc (Breivik et al., 2002). Moreover, PCBs can be introduced into environment from waste incineration processes and occur as byproducts in a wide variety of chemical processes. In recent years, PCBs, especially dioxin-like and indicator congeners are of great environmental concern because of their high persistence, lipophilic properties, bioaccumulation, and toxicity to the ecosystem and human (Manodori et al., 2006; Xing et al., 2005). Because of these properties, PCBs have been banned since the end of 1970s in the USA and Europe and have been listed as serious threats to health and the environment by the Stockholm Convention (May 22, 2001). For these reasons, the concentrations, transport, fate and environmental risk of PCBs in various environmental media have been extensively studied (Pikkarainen, 2007; Manodori et al., 2006; Zhao et al., 2007; Howell et al., 2008). Since sludge is widely recognized as an important matrix of persistent organic pollutants, including PCBs, this class of compounds has been well documented in other countries and regions (Souze Pereira and Kuch, 2005; 
Eljarrat et al., 2003; Stevens et al., 2003).

Many studies on the PCBs contamination in China were focused on the atmosphere (Lammel et al., 2007), soils (Ren et al., 2007), river sediments (He et al., 2006; Liu et al., 2007), biota (Zhao et al., 2005), and human milk (Zhao et al., 2007). However, little information on PCBs is available in the sludge of WWTPs in China. The main objectives of the present study are to investigate the levels and distribution of dioxin-like and indicator $\mathrm{PCB}$ congeners and total PCBs (from Mono-CBs to Deca-CB) in sewage sludge of WWTPs of Beijing and to identify their possible sources in sludge.

\section{Materials and methods}

\subsection{Standards and reagents}

All solvents were of pesticide residue grade and purchased from Tedia Co., USA. Silica gel (100-200 mesh) was obtained from Qingdao Haiyang Chemical Co., China. Permeable gel (SX-3 Bio-Beads, 200-400 mesh) was purchased from Bio-Rad Co., USA.

Calibration standard solutions, ${ }^{13} \mathrm{C}$-labeled surrogate standards and injection standards complying with EPA method 1668A for PCBs analysis were purchased from Cambridge Isotope Laboratories, USA.

\subsection{Sample collection and pretreatment}

The sewage sludge samples were collected from WWTPs in Beijing in May, 2007, and their related details are shown in Table 1. Samples were packed in aluminum foil, then directly delivered to the laboratory and stored in a refrigerator. Sludge samples were freeze-dried for $48 \mathrm{~h}$ and mixed homogenously before analysis.

\subsection{Extraction and clean-up}

The analysis of the PCB congeners was performed according to USEPA method 1668A. Approximately 2-3 g dry weight (dw) sludge samples was mixed homogeneously with appropriate anhydrous sodium sulphate in a glass thimble. The samples were spiked with a mixture of $1 \mathrm{ng}{ }^{13} \mathrm{C}$-labeled PCB surrogate standards and Soxhletextracted for $24 \mathrm{~h}$ with toluene.

The concentrated extracts were subsequently purified

Table 1 Characteristics of the wastewater treatment plants (WWTPs)

\begin{tabular}{lllll}
\hline Sample & $\begin{array}{l}\text { Wastewater } \\
\text { type }\end{array}$ & Process & $\begin{array}{l}\text { Capacity } \\
\left(\mathrm{m}^{3} / \mathrm{d}\right)\end{array}$ & $\begin{array}{l}\text { Digestion } \\
\text { treatment }\end{array}$ \\
\hline S1 & Domestic & $\mathrm{OD}$ & $2.0 \times 10^{5}$ & - \\
S2 & Domestic & $\mathrm{A}^{2} / \mathrm{O}$ & $4 \times 10^{4}$ & Aerobic \\
S3 & Domestic & $\mathrm{A}^{2} / \mathrm{O}$ & $2.0 \times 10^{5}$ & - \\
S4 & Domestic & $\mathrm{SBR}$ & $8 \times 10^{4}$ & - \\
S5 & Domestic & $\mathrm{A}^{2} / \mathrm{O}$ & $6.0 \times 10^{5}$ & - \\
S6 & Domestic & $\mathrm{MBR}$ & $1.0 \times 10^{5}$ & Anaerobic \\
S7 & Industrial/Domestic $(1: 1)$ & $\mathrm{A}^{2} / \mathrm{O}$ & $5.0 \times 10^{5}$ & Anaerobic \\
S8 & Industrial/Domestic $(1: 1)$ & $\mathrm{A}^{2} / \mathrm{O}$ & $5.0 \times 10^{5}$ & Anaerobic \\
\hline
\end{tabular}

OD: oxidation ditch; $\mathrm{A}^{2} / \mathrm{O}$ : anaerobic-anoxic-oxic; SBR: sequencing batch reacter; MBR: membrane biological reactor. and fractionated by multi-layer silica gel, gel permeable column (GPC) and basic alumina chromatographic columns in turn (Guo et al., 2008). A multi-layer silica column (from bottom to top: $1 \mathrm{~g}$ activated silica, $2 \mathrm{~g}$ $\mathrm{AgNO}_{3}$ silica, $1 \mathrm{~g}$ activated silica, $3 \mathrm{~g}$ basic silica, $1 \mathrm{~g}$ activated silica, $8 \mathrm{~g}$ acidic silica, $1 \mathrm{~g}$ activated silica, and $2 \mathrm{~cm}$ anhydrous sodium sulphate) was used and eluted with $100 \mathrm{~mL} n$-hexane. The second column was a gel permeable column packed with $30 \mathrm{~g}$ SX-3 Bio-Beads. Before loading the extracts, the column was pre-washed with $50 \mathrm{~mL}$ of $50 \%$ dichloromethane (DCM) in $n$-hexane. Samples were eluted with $120 \mathrm{~mL}$ of $50 \%$ DCM in $n$ hexane, the first $50 \mathrm{~mL}$ effluent was discarded and the following $70 \mathrm{~mL}$ effluent was collected. The extracts were further concentrated and passed through a column with 8 $\mathrm{g}$ basic alumina and $2 \mathrm{~cm}$ anhydrous sodium sulphate for further purification. Samples were then eluted with $100 \mathrm{~mL}$ of 5\% DCM in $n$-hexane (PCBs and PCNs eluted in the same fraction). The final fractions were concentrated to $20 \mu \mathrm{L}$ with gentle stream of nitrogen. Prior to injection, ${ }^{13} \mathrm{C}$-labeled injection standards of PCBs were added for calculation of recovery.

\subsection{Instrumental analysis}

High resolution gas chromatography/high resolution mass spectrometry (HRGC-HRMS) measurements were carried out using an Agilent 6890 gas chromatography (GC) coupled with an Autospec Ultima mass spectrometer (MS) (Waters Micromass, UK) on a resolution of approximately 10000 with $\mathrm{EI}^{+}$mode $(35 \mathrm{eV})$. HRMS was operated in selected ion monitoring (SIM) mode and the ion source temperature was $270^{\circ} \mathrm{C}$.

A DB-5 $(60 \mathrm{~m} \times 0.25 \mathrm{~mm} \times 0.25 \mu \mathrm{m}$ film thickness $)$ capillary column was used for the determination of PCB congeners. The column temperature initiated at $120^{\circ} \mathrm{C}(1$ min), then increased to $150^{\circ} \mathrm{C}$ at $30^{\circ} \mathrm{C} / \mathrm{min}$, and $300^{\circ} \mathrm{C}(5$ $\mathrm{min}$ ) at $2.5^{\circ} \mathrm{C} / \mathrm{min}$. The injector and transfer line temperatures were 270 and $290^{\circ} \mathrm{C}$, respectively. The carrier gas was helium at $1.2 \mathrm{~mL} / \mathrm{min}$. Injection volume was $1 \mu \mathrm{L}$ in splitless mode.

\subsection{Quality assurance and quality control}

The procedures described above were controlled strictly by the analysis of procedural blank samples as well as the recoveries of ${ }^{13} \mathrm{C}$-labeled compounds in each sample. Before extraction, the whole Soxhlet apparatus were preextracted for over $6 \mathrm{~h}$ with $250 \mathrm{~mL}$ toluene. Method blanks were monitored to evaluate the contamination. The results were free of PCB homologues except PCB-28 and PCB-52, which were 5\% lower than the lowest sample concentrations. All sample concentrations in this study were not corrected with blank value.

The recovery in samples was obtained using the ${ }^{13} \mathrm{C}$ labeled PCBs standards to ensure the repeatability of the results. Recoveries ranged from $62 \%$ to $114 \%$. The limit of detection (LOD) for individual congener was defined by a signal to noise ratio of $3: 1$. The concentration of PCB congener in sample was destined for LOD value when it was lower than LOD value. 


\section{Results and discussion}

\subsection{PCB concentrations in sludge samples}

The analytical results of PCB concentrations for sewage sludge samples collected from 8 WWTPs in Beijing are presented in Tables 2 and 3. The total PCBs concentration (from Mono-CBs to Deca-CB) ranged from 65.6 to 157 $\mathrm{ng} / \mathrm{g} \mathrm{dw}$ with an average of $101 \mathrm{ng} / \mathrm{g} \mathrm{dw}$. Toxic equivalency (TEQ) concentrations of twelve dioxin-like PCBs are calculated using World Health Organization toxic equivalent factors (WHO-TEFs) (Van den Berg et al., 1998). The WHO-TEQ values are not greater than $1 \mathrm{pg} / \mathrm{g} \mathrm{dw}$, which was far from the limit set at $100 \mathrm{pg}$ TEQ $/ \mathrm{g}$ dw for agricultural purposes (GB18918-2002). From the results of total PCBs, no correlation is observed between capacity or the treatment type of the WWTP and PCBs burden.

The high levels are detected at S7 (135.3 ng/g dw) and S8 (157.3 ng/g dw), both plants had a $50 \%$ input of industrial effluent, suggesting a possible industrial effluent discharge source. Similar influence has also been found on total polychlorinated naphthalenes (PCNs) of the same sludge samples (Guo et al., 2008). According to the Chinese regulation (GB18918-2002), PCB levels should be less than $200 \mathrm{ng} / \mathrm{g}$ dw for agricultural use. Therefore, the PCB values in sewage sludge in Beijing are lower than the maximum permissible concentration and are suitable for agricultural purposes.

The concentrations detected in this study are lower in sewage sludge from 14 wastewater treatment plants in UK (110-440 ng/g dw) (Stevens et al., 2003), but are 1000-fold lower than in Brazilian sludge (57600-145000 ng/g dw) (Souze Pereira and Kuch, 2005), which might be explained the contamination of technical PCB mixtures.

As regards indicator $\mathrm{PCBs}$, the total seven indicators PCB concentrations detected in sludge in Beijing (7.5-19.4 $\mathrm{ng} / \mathrm{g} \mathrm{dw}$ ) are within the range reported in other similar studies which gave contents between 0.19 to $72.5 \mathrm{ng} / \mathrm{g}$ dw (Souze Pereira and Kuch, 2005; Eljarrat et al., 2003). Blanchard et al. (2004) reported values for total indicator PCBs between 130 and $1070 \mathrm{ng} / \mathrm{g} \mathrm{dw}$, which is somewhat higher than the levels obtained in this study.

\subsection{PCB homologue profiles and possible sources}

Figure 1 presents PCB homologue profiles derived from sewage sludge samples. No significant changes have been found in all sludge samples. Tri-CBs $(23.8 \%-46.9 \%)$ and Tetra-CBs $(24.4 \%-44.3 \%)$ are the most dominant homologues of PCBs, followed by Di-CBs (6.7\%-25.7\%) and Penta-CBs $(8.2 \%-13.6 \%)$. The contribution of other high-

Table 2 Concentrations of dioxin-like PCBs in sludges from WWTPs in Beijing, China (pg/g dw)

\begin{tabular}{|c|c|c|c|c|c|c|c|c|}
\hline PCB congener & $\mathrm{S} 1$ & $\mathrm{~S} 2$ & S3 & S4 & S5 & S6 & S7 & S8 \\
\hline PCB-77 & 106 & 84.2 & 106 & 199 & 136 & 138 & 166 & 161 \\
\hline PCB-81 & 6.5 & 5.2 & 10.3 & 8.7 & 8.1 & 11.7 & 13.6 & 13.6 \\
\hline PCB-105 & 290 & 200 & 399 & 512 & 279 & 309 & 334 & 334 \\
\hline PCB-114 & 26.6 & 18.5 & 33.8 & 46.8 & 27.3 & 27.6 & 37.3 & 36.2 \\
\hline PCB-118 & 614 & 412 & 841 & 1046 & 585 & 657 & 690 & 699 \\
\hline PCB-123 & 52.8 & 41.8 & 76.5 & 97.1 & 52.3 & 54.6 & 72.1 & 73.0 \\
\hline PCB-126 & 3.6 & 3.3 & 3.6 & 7.1 & 4.5 & 3.6 & 7.6 & 7.2 \\
\hline PCB-156 & 60.4 & 44.7 & 105 & 106 & 63.3 & 63.2 & 80.4 & 79.2 \\
\hline PCB-157 & 14.2 & 11.1 & 24.4 & 26.2 & 15.4 & 14.3 & 19.1 & 19.6 \\
\hline PCB-167 & 20.4 & 15.8 & 36.3 & 39.6 & 23.4 & 22.1 & 32.0 & 31.1 \\
\hline PCB-169 & 0.8 & 0.7 & 0.8 & 1.5 & 1.1 & 0.8 & 2.5 & 2.4 \\
\hline PCB-189 & 3.4 & 3.3 & 5.2 & 6.1 & 3.9 & 2.9 & 13.4 & 12.6 \\
\hline Sum DL-PCBs & 1199 & 841 & 1641 & 2096 & 1199 & 1305 & 1468 & 1469 \\
\hline WHO-TEQ & 0.53 & 0.45 & 0.59 & 1.00 & 0.62 & 0.54 & 0.98 & 0.94 \\
\hline
\end{tabular}

Table 3 Concentrations of indicator and homologue PCBs in sluges from WWTPs in Beijing, China (ng/g dw)

\begin{tabular}{|c|c|c|c|c|c|c|c|c|}
\hline PCB congener & $\mathrm{S} 1$ & $\mathrm{~S} 2$ & $\mathrm{~S} 3$ & $\mathrm{~S} 4$ & S5 & S6 & S7 & S8 \\
\hline PCB-28 & 5.86 & 5.00 & 10.89 & 7.94 & 9.66 & 12.61 & 8.01 & 10.96 \\
\hline PCB-52 & 0.93 & 0.68 & 0.87 & 1.39 & 0.79 & 0.95 & 3.88 & 4.64 \\
\hline PCB-101 & 0.48 & 0.36 & 0.68 & 0.84 & 0.47 & 0.69 & 1.19 & 1.32 \\
\hline PCB-118 & 0.61 & 0.41 & 0.84 & 1.05 & 0.59 & 0.66 & 0.69 & 0.70 \\
\hline PCB-138 & 0.50 & 0.48 & 0.90 & 0.97 & 0.70 & 0.78 & 0.73 & 0.76 \\
\hline PCB-153 & 0.55 & 0.42 & 0.89 & 0.97 & 0.73 & 0.78 & 0.80 & 0.86 \\
\hline PCB-180 & 0.13 & 0.11 & 0.15 & 0.24 & 0.21 & 0.19 & 0.14 & 0.15 \\
\hline Sum indicator PCBs & 9.07 & 7.46 & 15.22 & 13.39 & 13.16 & 16.67 & 15.44 & 19.39 \\
\hline Mono-CBs & 0.06 & 0.08 & 0.05 & 0.29 & 0.23 & 0.05 & 0.06 & 1.93 \\
\hline $\mathrm{Di}-\mathrm{CBs}$ & 11.29 & 17.58 & 9.34 & 6.60 & 8.89 & 19.33 & 17.67 & 19.62 \\
\hline Tri-CBs & 21.38 & 21.45 & 38.84 & 28.55 & 28.27 & 56.40 & 32.17 & 43.81 \\
\hline Tetra-CBs & 30.17 & 20.93 & 20.21 & 43.76 & 18.23 & 29.27 & 34.09 & 38.91 \\
\hline Penta-CBs & 7.77 & 5.59 & 9.03 & 13.42 & 5.41 & 10.89 & 13.63 & 14.73 \\
\hline Hexa-CBs & 2.62 & 2.10 & 4.39 & 4.89 & 2.91 & 3.90 & 4.27 & 4.51 \\
\hline Hepta-CBs & 0.36 & 0.30 & 0.41 & 0.67 & 0.42 & 0.62 & 1.54 & 1.56 \\
\hline Octa-CBs & 0.23 & 0.19 & 0.26 & 0.40 & 0.28 & 0.30 & 5.38 & 5.09 \\
\hline Nona-CBs & 0.04 & 0.03 & 0.04 & 0.06 & 0.06 & 0.03 & 4.20 & 4.35 \\
\hline Deca-CB & 0.22 & 0.08 & 0.18 & 0.23 & 0.90 & 0.10 & 22.30 & 22.81 \\
\hline Total PCBs & 74.13 & 68.32 & 82.75 & 98.86 & 65.60 & 120.9 & 135.3 & 157.3 \\
\hline
\end{tabular}




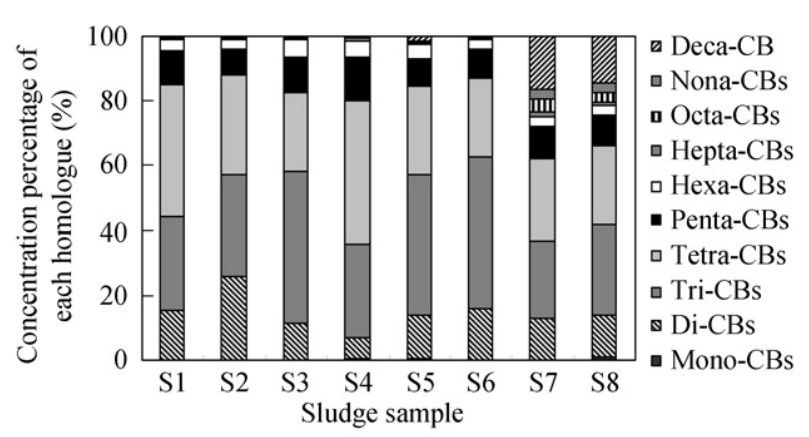

Fig. 1 PCB homologue profiles of the sewage sludge samples.

chlorinated PCBs (from Octa-CBs to Nona-CBs) is less than $7 \%$ in all samples. The result reveals that PCB in sludge samples were predominated by low chlorinated PCBs. However, it must be noted that Deca-CB (PCB209) has remarkably higher absolute concentrations and accounts for $15 \%$ in both S7 and S8 samples. As it is well known, because higher chlorinated homologues are less volatile and more bound to particles, they tend to resemble more accurately the estimated historical usage pattern and remain more closely to their sources regions (Meijer et al., 2003). Consequently, the observed higher concentration of Deca-CB in S7 and S8 samples probably can be explained deposition into sewage sludge from the inputs of industrial effluent during the wastewater treatment processes. Because PCB-209 was not present in the most common PCB mixtures (Breivik et al., 2002; Howell et al., 2008), knowledge on distribution and sources of this congener is very limited. Howell et al. (2008) indicated that the unusually high fraction of PCB-209 was found from samples in Houston Ship Channel in Texax to unusual Aroclor mixtures used in the history or contemporary sources from local industry, while Ishikawa et al. (2007) confirmed PCB-209 was generated during the thermal process.

The observed homologue profiles relate reasonably well with PCB production. In China, about 10000 tons of PCBs were produced since 1965 to 1974 , within 9000 tons as trichlorobiphenyl and 1000 tons as pentachlorobiphenyl (Xing et al., 2005). Trichlorobiphenyl, known as PCB3, was utilized in electric capacitor production and contained $42 \%$ chlorine, which had similar composition with Aroclor 1242. While pentachlorobiphenyl (PCB5), employed as additives in paint and contained $53 \%$ chlorine, was similar to Aroclor 1254 (Xing et al., 2005; Jiang et al., 1997). Figure 2 shows the homologue distribution in sewage sludge samples in the present study (Deca-CB was not taken into account) in comparison to the PCB technical mixtures. Compositons of PCB homologues in sewage sludge are in good agreement with those of Aroclor 1242. This indicates that the PCB3 products may be one of the major sources of PCBs in sewage sludge. The results are quite different with the results reported by Souze Pereira and Kuch (2005), in which both Brazilian samples show a homologue profile with the predominance of the penta$\mathrm{CB}$ to hepta-CB groups that indicate a contamination from technical PCB formulations like Clophen A50 and Clophen A60 or equivalent.

\subsection{PCB congener profiles}

The profiles of dioxin-like and indicator congeners are quite similar in all samples regardless of difference of wastewater types, as shown in Fig. 3. This indicates that these PCB congeners influenced either by domestic or industrial input that have similar isomer compositions. Among the 12 dioxin-like PCB congeners, obviously, PCB-118, -105 and -77 were the predominant congeners (Table 2 and Fig. 3a), with the average contributions of $49 \%, 24 \%$, and $10 \%$, respectively. However, the PCBTEQ values are exclusively dominated by PCB-126 (71\% of the total PCB-TEQs) for it having a high TEF value. This observation agrees with the profile of dioxin-like PCB congeners found in sludges from Catalonia by Eljarrat et al. (2003). However, as regard to indicator PCB congeners, contribution of each congener has no significant difference in sludges from Catalonia (Eljarrat et al., 2003), while the results of indicator PCB congeners (Fig. 3b, Table 3 ) in the present study show that PCB-28 was the most abundant congener, which accounts for approximately $65 \%$ of the total indicator PCBs.

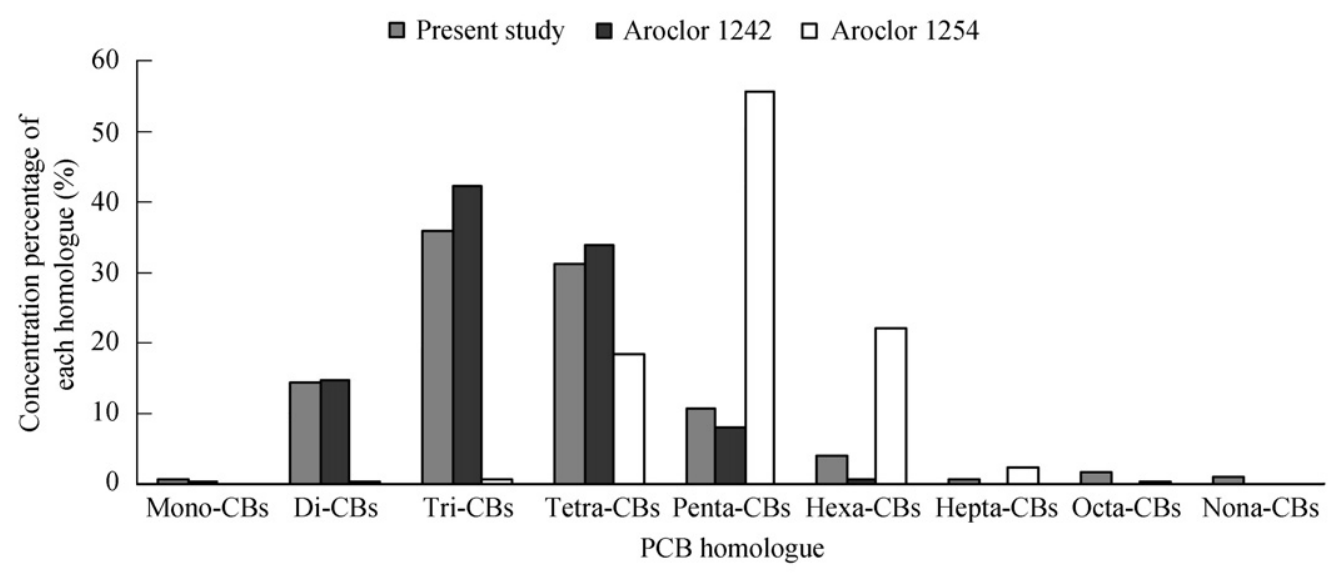

Fig. 2 Distribution of PCB homologue groups (except Deca-CB) in sludges of WWTPs in composition with Aroclor commercial formulations (Aroclor 1242 and 1254) 

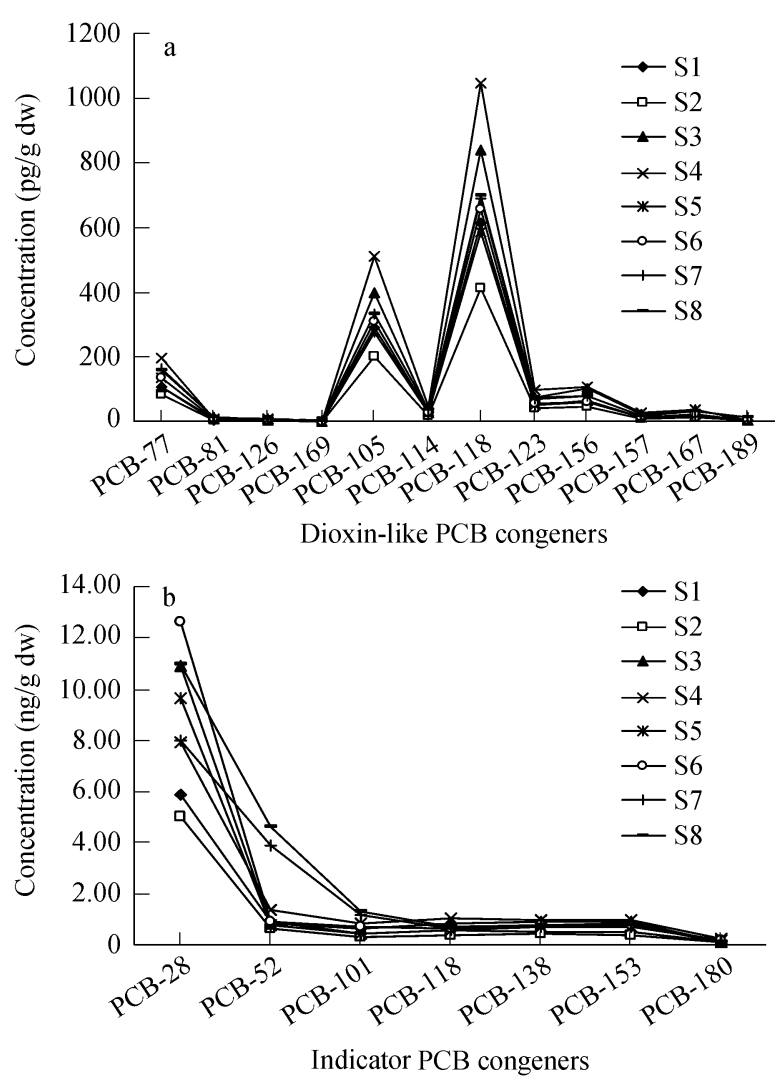

Fig. 3 Profiles of dioxin-like (a) and indicator (b) PCB congeners in sludge of WWTPs

\section{Conclusions}

The present study reveals a moderate contamination of urban WWTPs in Beijing. Dioxin-like PCBs are detected in all the samples, but the TEQ levels are lower than 1 $\mathrm{pg} / \mathrm{g} \mathrm{dw}$, which is far from the limit set at $100 \mathrm{pg} / \mathrm{g}$ TEQ $\mathrm{dw}$ for agricultural purposes. PCB homologue profiles are dominated by Tri-CBs, followed by Tetra-CBs and Di-CBs. The extremely high concentration of Deca-CB (PCB-209) detected in S7 and S8 samples might be due to the local industrial inputs. The observed homologue profiles relate reasonably well with one of the Chinese PCB commercial products. Dioxin-like and indicator PCB congener profiles in all samples are similar.

\section{Acknowledgments}

This work was supported by the Key Project of Chinese Academy of Sciences (No. KZCX2-YW-420), the National Basic Research Program (973) of China (No. 2009CB421606) and the National Natural Science Foundation of China (No. 20621703).

\section{References}

Blanchard M, Teil M J, Ollivon D, Garban B, Chesterikoff C, Chevreuil M, 2001. Origin and distribution of polyaromatic hydrocarbons and polychlorobiphenyls in the urban effluents to wastewater treatment plants of the Paris area (France). Water Research, 35(15): 3679-3687.

Blanchard M, Teil M J, Ollivon D, Legenti L, Chevreuil M, 2004.
Polycyclic aromatic hydrocarbons and polychlorobiphenyls in wastewaters and sewage sludges from the Paris area (France). Environmental Research, 95: 184-197.

Breivik K, Sweetman A, Pacyna J M, Jones K C, 2002. Towards a global historical emission inventory for selected PCB congeners - a mass balance approach: I. Global production and consumption. Science of the Total Environment, 290: 181-198.

Cai Q Y, Mo C H, Wu Q T, Zeng Q Y, Katsoyiannis A, 2007. Occurrence of organic contaminants in sewage sludges from eleven wastewater treatment plants, China. Chemosphere, 68: 1751-1762.

Eljarrat E, Caixach J, Rivera J, 1997. Effects of sewage sludges comtaminated with polychlorinated dibenzo- $p$ dioxins, dibenzofurans, and biphenyls on agricultural soils. Environmental Science and Technology, 31: 2765-2771.

Eljarrat E, Caixach J, Rivera J, 2003. A comparison of TEQ contributions from PCDDs, PCDFs and dioxin-like PCBs in sewage sludges from Catalonia, Spain. Chemosphere, 51: 595-601.

Guo L, Zhang B, Xiao K, Zhang Q H, Zheng M H, 2008. Levels and distributions of polychlorinated biphenyls in sewage sludge of urban wastewater treatment plants. Chinese Science Bulletin, 2008, 53: 508-513.

Harrison E Z, Oakes S R, Hysell M, Hay A, 2006. Organic chemicals in sewage sludges. Science of the Total Environment, 367: 481-497.

He M C, Sun Y, Li X R, Yang Z F, 2006. Distribution patterns of nitrobenzenes and polychlorinated biphenyls in water, suspended particulate matter and sediment from mid- and down-stream of the Yellow River (China). Chemosphere, 65: 365-374.

Howell N L, Suarez M P, Rifai H S, Koenig L, 2008. Concentrations of polychlorinated biphenyls (PCBs) in water, sediment, and aquatic biota in the Houston Ship Channel, Texas. Chemosphere, 70: 593-606.

Ishikawa Y, Noma Y, Yamamoto T, Mori Y, Sakai S, 2007. PCB decomposition and formation in thermal treatment plant equipment. Chemosphere, 67: 1383-1393.

Jiang K, Li L J, Chen Y D, Jin J, 1997. Determination of $\mathrm{PCDD} / \mathrm{Fs}$ and dioxin-like PCBs in Chinese commercial $\mathrm{PCBs}$ and emissions from a testing $\mathrm{PCB}$ incinerator. Chemosphere, 34: 941-950.

Katsoyiannis A, Samara C, 2004. Persistent organic pollutants (POPs) in the sewage treatment plant of Thessaloniki, northern Greece: occurrence and removal. Water Research, 38: 2685-2698.

Lammel G, Ghim Y S, Grados A, Gao H, Hhnerfuss H, Lohmann $\mathrm{R}, 2007$. Levels of persistent organic pollutants in air in China and over the Yellow Sea. Atmosphere Environment, 41: 452-464.

Lazzari L, Sperni L, Bertin P, Pavoni B, 2000. Correlation between inorganic (heavy metals) and organic (PCBs and PAHs) micropollutant concentrations during sewage sludge composting processes. Chemosphere, 41: 427-435.

Liu H X, Zhang Q H, Wang Y W, Cai Z W, Jiang G B, 2007. Occurrence of polychlorinated dibenzo-p-dioxins, dibenzofurans, and biphenyls pollution in sediments from the Haihe River and Dagu Drainage River in Tianjin City, China. Chemosphere, 68: 1772-1778.

Manodori L, Gambaro A, Moret I, Capodaglio G, Cairns W R L, Cescon P, 2006. Seasonal evolution of gas-phase PCB concentrations in the Venice Lagoon area. Chemosphere, 62: 449-458. 
Meijer S N, Ockenden W A, Sweetman A, Breivik K, Grimalt J O, Jones K C, 2003. Global distribution and budget of PCBs and $\mathrm{HCB}$ in background surface soils: implications for sources and environmental processes. Environment Science and Technology, 37: 667-672.

Pikkarainen A L, 2007. Polychlorinated biphenyls and organochlorine pesticides in Baltic Sea sediments and bivalves. Chemosphere, 68: 17-24.

Ren N Q, Que M X, Li Y F, Liu Y, Wan X N, Xu D D, Sverko E, Ma J M, 2007. Polychlorinated biphenyls in Chinese surface soils. Environment Science and Technology, 41: 3871-3876.

Souza Pereira M de, Kuch B, 2005. Heavy metals, PCDD/F and PCB in sewage sludge samples from two wastewater treatment facilities in Rio de Janeiro State, Brazil. Chemosphere, 60: 844-853.

Stevens J L, Northcott G L, Stern G A, Tomy G T, Jones K C, 2003. PAHs, PCBs, PCNs, organochlorine pesticides, synthetic musks, and polychlorinated $n$-alkanes in U.K. sewage sludge: survey results and implications. Environment Science and Technology, 37: 462-467.

Van den Berg M, Birnbaum L, Bosveld A T C, Brunström B, Cook P, Feeley M, Giesy J P, Hanberg A, Hasegawa R, Kennedy S W et al., 1998. Toxic equivalency factors (TEFs) for PCBs, PCDDs, PCDFs for humans and wildlife. Environmental Health Perspectives, 106: 775-792.

Xing Y, Lu Y L, Dawson R W, Shi Y J, Zhang H, Wang T Y, Liu W B, Ren H C, 2005. A spatial temporal assessment of pollution from PCBs in China. Chemosphere, 60: 731-739.

Zhao G F, Xu Y, Li W, Han G G, Ling B, 2007. PCBs and OCPs in human milk and selected foods form Luqiao and Pingqiao in Zhejiang, China. Science of the Total Environment, 378: 281-292.

Zhao X R, Zheng M H, Liang L N, Zhang Q H, Wang Y W, Jiang G B, 2005. Assessment of PCBs and PCDD/Fs along the Chinese Bohai Sea coastline using mollusks and bioindicators. Archives of Environmental Contamination and Toxicology, 49: 178-185. 